\title{
Mapping Chinese supply
}

Mikael Höök, Department of Earth Sciences, Uppsala University, Uppsala, Sweden

Documenting the emissions and net energy of a crude supply could be essential to meeting national emission and energy security targets. Using data from hundreds of fields worldwide, a well-to-refinery study presents a high-granularity profile of China's crude oil supply in terms of emissions and energy return on input.

Understanding the varying emissions and net energy return of a nation's oil supply might be critical towards an effective transition to low-carbon economies. However, oversimplifications or generalizations based on aggregated statistics have been a deterrent from more nuanced insights into crucial details that underpin oil use and its associated carbon emissions. Writing in Nature Energy, Mohammad Masnadi and colleagues across the US (ref. 1) make important contributions towards deepening and widening our understanding of carbon emissions associated with oil by mapping the well-to-refinery emissions and net energy of China's varied crude oil supply.

The researchers use project-specific and field-specific data in a granular, engineering-based, bottom-up approach to capture physical drivers of emissions and production. They report that about $90 \%$ of all Chinese crude oil is supplied from fields that emit 1.5-13.5 g CO$_{2}$ e per MJ while the remainder comes from fields with high emissions (13.5 to $>40 \mathrm{CO}_{2} \mathrm{e}$ per MJ) due to gas flaring and energy-intensive enhanced oil recovery (EOR) methods. The highly skewed carbon intensity distribution illustrates that oil imports from different parts of the world have very different impacts on emissions (http://go.nature.com/2Fj1LkU).

Emissions calculators, life cycle assessments (LCAs), and energy system models often rely on parameters, such as production costs or carbon intensities, derived from highly aggregated datasets such as national or sectorial averages. This is understandable as a legacy of times when most oil production worldwide was homogenous and chiefly relied on onshore fields that contained conventional oil with largely similar methods of recovery. However, in the wake of decreasing new conventional oil discoveries (Fig. 1a), the last two decades have seen global oil use become more diversified with national supplies being made up of increasingly heterogeneous oil resources and varied production methods. Increased reliance on oil sands, extra-heavy oil, ultra-deep water, light tight oil from shale formations, and other non- 
traditional oil resources have made current production more diverse and made the old topdown approaches for modelling to inform policy less suitable (Refs. 3, 4, 5). Masnadi and colleagues show that realistic handling of energy and associated emissions requires embracing the fact that countries, producers, and even oil fields are individually different, with wide deviations from the 'average' or aggregate picture. They report significant differences in existing LCA databases, such as Ecoinvent (ref. 6), which are likely attributable to these databases' omission of technical factors that affect greenhouse gas emission intensities.

Figure 1. Observed and projected growth in share of global unconventional production and Chinese oil imports.

a

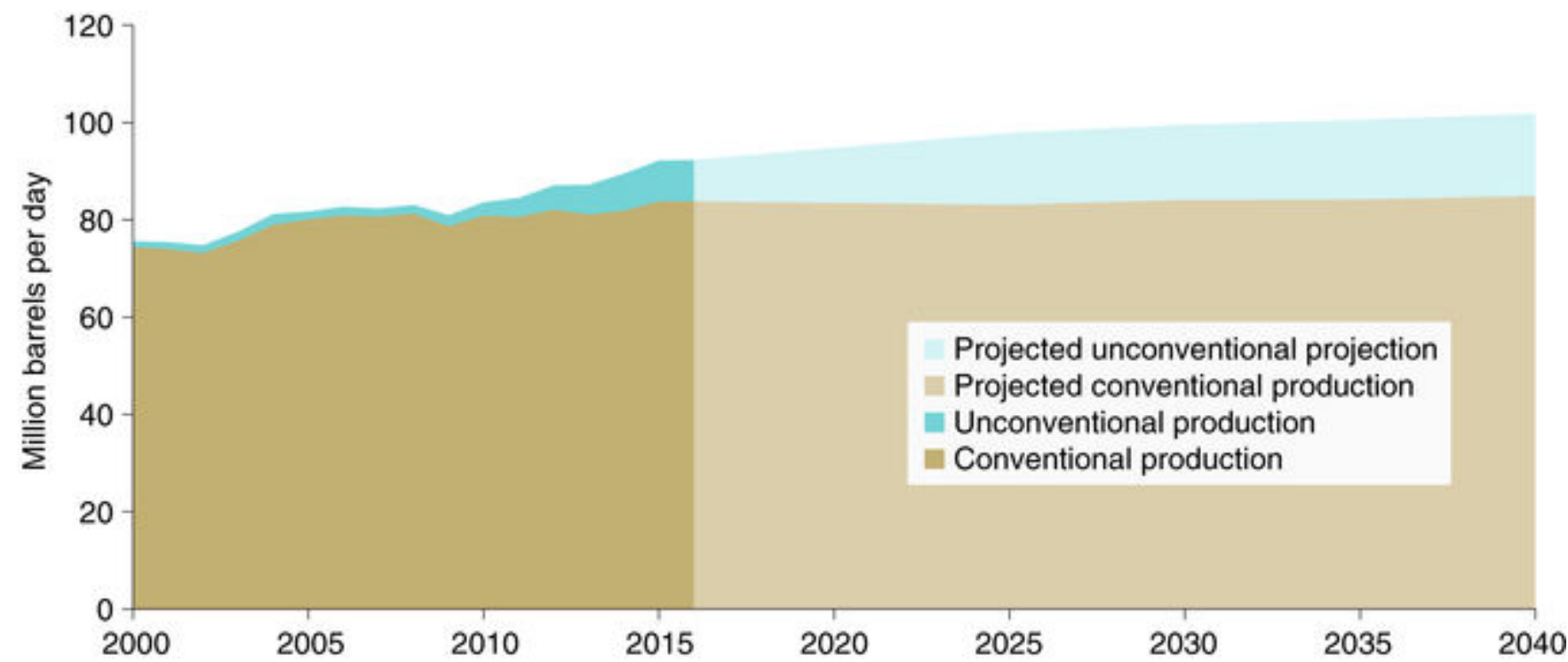

b

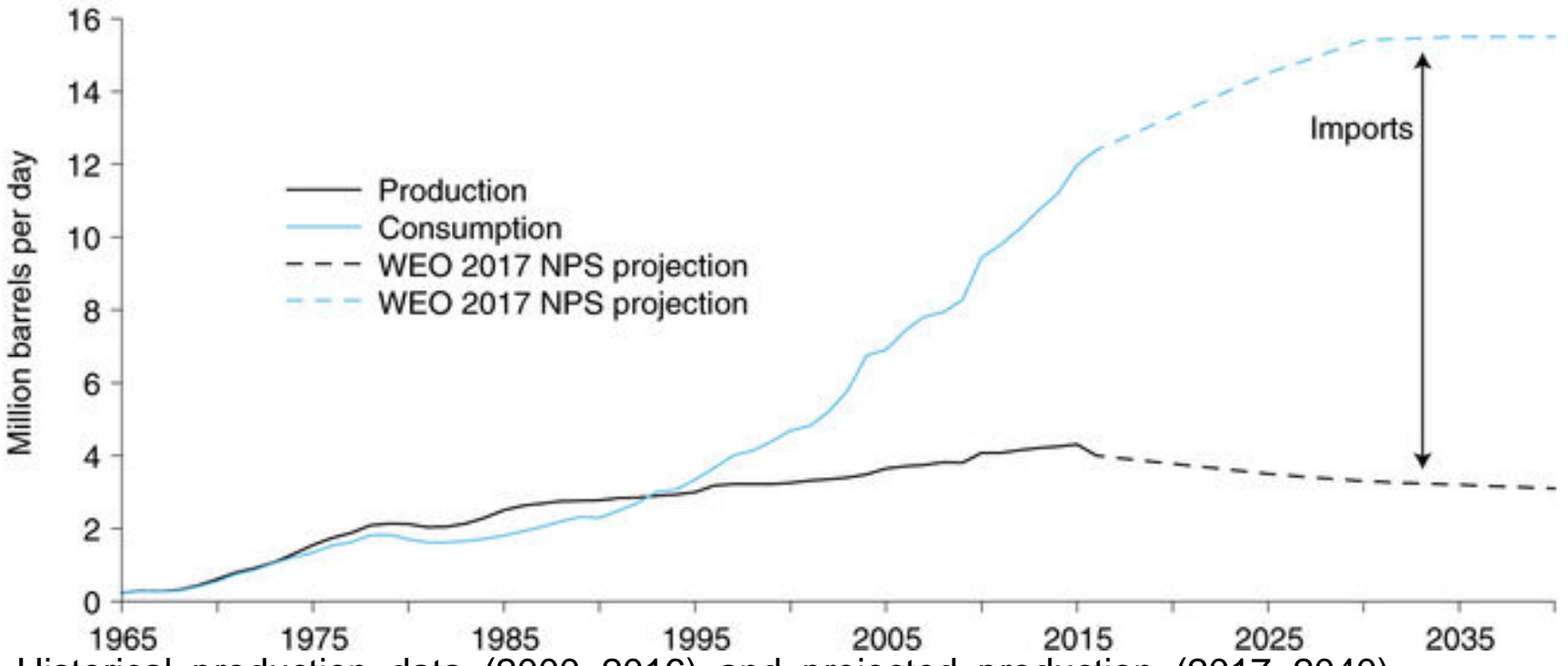

a, Historical production data (2000-2016) and projected production (2017-2040) from IEA World Energy Outlook 2017, New Policies Scenario (NPS) (Ref. 2) b, Historical production and consumption data in China up to 2016 (ref. 8) and IEA NPS projections to 2040 (ref. 2). 
Chinese emissions from liquid fuel consumption have roughly doubled within 20 years (ref. z) and oil use is still increasing fairly rapidly. In the future, Chinese reliance on imported oil is expected to become even greater (Fig. 1b), making Chinese impacts on world oil markets rise even higher. Not only is China currently the largest carbon emitter in the world, it is also a major actor in the global fossil-fuel trade. As the 'world's factory', China exports a large volume of products and services to the rest of the world, making its domestic energy system deeply intertwined with every aspect of the global embodied and direct energy trade (Refs. 9, 10).

While recent deployments of state-of-the-art low-carbon technologies have made important contributions to reducing the carbon dependence of the Chinese economy (Ref. 11), the future oil import structure of China still matters significantly. The data presented by Masnadi and co-authors indicates that the impact of replacing or phasing out just the most carbonintensive $10 \%$ of Chinese oil imports could be significant — not just for continuing climateinformed energy strategies but also for geopolitical and energy security reasons, such as avoiding potentially risky suppliers in regions with security concerns. Improved understanding of Chinese oil policies and import preferences are therefore vital for modelling emission trends on local and global scales with a nuance that can inform policy realistically.

Lack of access to reliable public data can be a critical hindrance in developing data-intensive bottom-up models of crude oil supply such as that from Masnadi and colleagues. Improving access to data for researchers is crucial and that should include both more transparent reporting on oil production and trade, but also better emission accounting of fossil-fuel resources such as shale.

Bottom-up modelling based on data-intensive estimates may lead to increased complexity for analysts, but as Masnadi and colleagues demonstrate it is a viable method for capturing and improving our understanding of the strong interlinkages that influence the development of society and the energy systems that power national economies, growth and development. Research approaches such as this, capable of tying energy, climate, engineering, and other factors together, should be encouraged for improving planning and for informing policy to minimize emissions in the long and short term.

\section{References:}

1. Masnadi, M. S. et al., 2018. Well-to-refinery emissions and net-energy analysis of China's crude-oil supply. Nature Energy, 3:220-226. DOI: http://dx.doi.org/10.1038/s41560-018$\underline{0090-7}$

2. World Energy Outlook 2017 (OECD Publishing, IEA, 2017).

3. Miller, R.G., Sorrell, S.R., 2014. The future of oil supply. Philos Trans A Math Phys Eng Sci. 13; 372(2006): 20130179. DOI: http://dx.doi.org/10.1098/rsta.2013.0179

4. Sorrell, S., Speirs, J., Bentley, R., Miller, R.,, Thompson, E., 2012. Shaping the global oil peak: A review of the evidence on field sizes, reserve growth, decline rates and depletion rates. Energy, 37(1), 709-724. DOI: http://dx.doi.org/10.1016/i.energy.2011.10.010

5. Jakobsson, K, Bentley, R., Söderbergh, B., Aleklett, K., 2012. The end of cheap oil: Bottomup economic and geologic modeling of aggregate oil production curves. Energy Policy, 41(2), 860-870. DOI: http://dx.doi.org/10.1016/j.enpol.2011.11.073 
6. Wernet, G. et al., 2016. The ecoinvent database version 3 (part I): overview and methodology. The International Journal of Life Cycle Assessment 21, 1218-1230. DOI: https://doi.org/10.1007/s11367-016-1087-8

7. World Bank, 2017. CO 2 Emissions from Liquid Fuel Consumption. https://data.worldbank.org/indicator/EN.ATM.CO2E.LF.KT?locations=CN\&view=chart

8. BP, 2017. BP Statistical Review of World Energy

9. Tang, X., Jin, Y., Wang, X., Wang, J., McLellan, B., 2017. Will China's trade restructuring reduce $\mathrm{CO} 2$ emissions embodied in international exports? Journal of Cleaner Production, 161(9), 1094-1103. DOI: http://dx.doi.org/10.1016/j.jclepro.2017.05.069

10. Kucukvar, M., Cansev, B., Egilmez, G., Onat, N.C., Samadi, H., 2016. Energy-climatemanufacturing nexus: New insights from the regional and global supply chains of manufacturing industries. Applied Energy, 184(12), 889-904. DOI: http://dx.doi.org/10.1016/i.apenergy.2016.03.068

11. Guan, D., Klasen, S., Hubacek, K, Feng, K., Liu, Z., He, K., Geng, Y., Zhang, Q., 2014. Determinants of stagnating carbon intensity in China. Nature Climate Change 4, 1017-1023. DOI: http://dx.doi.org/10.1038/nclimate2388 